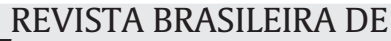

Systematics, Morphology and Biogeography

\section{Lopesia leandrae (Diptera, Cecidomyiidae), a new species of gall midge associated with Leandra ionopogon (Mart.) Cogn. (Melastomataceae), a native plant to Brazil}

\author{
Valéria Cid Maia \\ Museu Nacional, Quinta da Boa Vista, Rio de Janeiro, RJ, Brazil
}

\section{A R T I C L E I N F O}

\section{Article history:}

Received 18 February 2019

Accepted 12 April 2019

Available online 7 May 2019

Associate Editor: Andrzej Grzywacz

\section{Keywords:}

Insect-plant interaction

Morphology

Neotropical

Taxonomy

\begin{abstract}
A B S T R A C T
Lopesia leandrae (Diptera, Cecidomyiidae), a new galling species associated with Leandra ionopogon (Melastomataceae), a native plant species to Brazil, is described based on larva, pupal exuvia, male and female. L. leandrae galls were collected in an area of Atlantic Forest in Bertioga, state of São Paulo, Southeastern Brazil. The new species was compared to the other species of Lopesia.

(C) 2019 Sociedade Brasileira de Entomologia. Published by Elsevier Editora Ltda. This is an open access article under the CC BY-NC-ND license (http://creativecommons.org/licenses/by-nc-nd/4.0/).
\end{abstract}

\section{Introduction}

Leandra ionopogon (Mart.) Cogn. (Melastomataceae) is a native plant to Brazil, where it occurs in the Atlantic Forest and Cerrado and has been found from Bahia (Northeast Region) to Santa Catarina (South Region) (Flora do Brasil, 2019).

A single insect gall morphotype is known on this plant species. It was recorded by Maia et al. (2008), in an inventory of gall performed in the municipality of Bertioga ( $23^{\circ} 51^{\prime} 16^{\prime \prime} \mathrm{S}-46^{\circ} 08^{\prime} 19^{\prime \prime}$ W0), state of São Paulo (Southeastern Brazil), in areas occupied by Atlantic Forest (restinga physiognomy). The authors identified the inducer as Lopesia sp. (Diptera, Cecidomyiidae). This species induces globoid, green or red, hairy leaf galls (Fig. 77 in Maia et al., 2008).

Lopesia Rübsaamen, 1908 is a genus of gall midges known from 29 described species. Although it has a wide geographical distribution, most species (24) are from the Neotropical region (20 described from Brazil), while three are Afrotropical, one is Nearctic, and one is Australasian (Gagné and Jaschhof, 2017; Maia and Oliveira, 2018; Garcia and Urso-Guimarães, 2018).

In this study, a new species of Lopesia that induces globoid, reddish, hairy galls on leaves of $L$. ionopogon is described based on material from São Paulo.

\section{Material and methods}

Specimens (males, females, pupal exuviae and larvae) of the Cecidomyiidae Collection of the Museu Nacional/Universidade Federal do Rio de Janeiro (MNRJ) were studied. All of them are mounted on glass slides in Canada balsam. Adult morphological terminology follows Cumming and Wood (2009) and that of the larval and pupal stages follows Gagné (1989). Anatomical drawings were made with the use of a camera lucida attached to a phase contrast microscope. All drawings were scanned and then edited using Corel DRAW ${ }^{\circledR}$.

Measures of morphological structures were obtained using a microscope slide with scale from $0.01 \mathrm{~mm}$ to $5.0 \mathrm{~mm}$. The number of dorsal spines present from the second to the eight abdominal segments was recorded.

Lopesia leandrae, sp. n. (Figs. 1-13)

The new species was placed in Lopesia by presenting four or three-segmented palpi, R5 curved at its juncture with Rs, Rs situated near the midlength of $\mathrm{R} 1$, short female postabdomen and its cerci with many short, sensory setae, and larva with corniform terminal papillae, each on a terminal projection.

Diagnosis. Adults with 1st-11th antennal flagellomeres neck partially setulose in both sexes, 12th flagellomere with apical process entirely setulose in both sexes, three- or four-segmented palpi, all male circumfila with short loops similar in length, tarsal claw with two teeth, 8th male tergite narrow, elongated, with only basal pair of trichoid sensilla; pupa with antennal horn bifid, with inner margin not serrated, apical plate with a bilobed projection at 


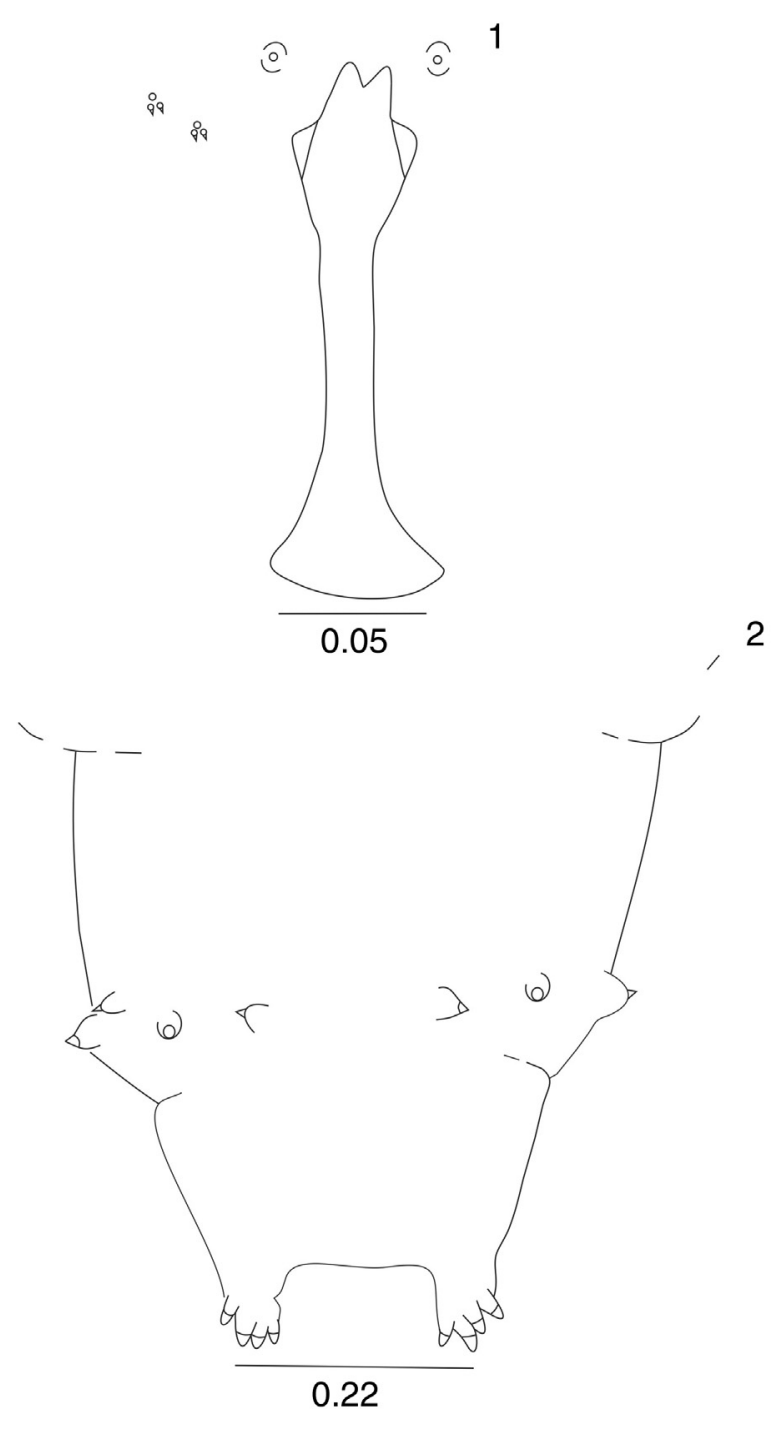

Figs. 1-2. Lopesia leandrae, sp. n., larva 1. Prothoracic spatula and associated papillae (ventral view). 2. 8th-9th abdominal segments (ventral view). Scale bars in $\mathrm{mm}$.

superior margin, prothoracic spiracle long, abdominal spiracles from 1st to 6th abdominal segments prominent, dorsal spines present; larva with spatula two-toothed and four pairs of corniform terminal papillae.

Larva. Fusiform and cylindrical body; $3.50-4.40 \mathrm{~mm}$ long $(n=13)$. Integument rough. Spatula (Fig. 1) $(n=9): 0.16-0.20 \mathrm{~mm}$ long, two-toothed, apical teeth triangular $0.020-0.033 \mathrm{~mm}$ long, stalk long $0.14-0.17 \mathrm{~mm}$; lateral projection present or absent, base wide. Two groups of three lateral papillae on each side of spatula (two pairs setose and one pair asetose in each group) (Fig. 1). Terminal segment (Fig. 2) ( $n=14): 0.21-0.28 \mathrm{~mm}$ long, bilobed at posterior margin, lobes $0.06-0.19 \mathrm{~mm}$ long, each one with four corniform papillae, all similar in length.

Pupa. Body length: $3.50-4.60 \mathrm{~mm}(n=14)$. Head (Fig. 3): apical setae $0.03-0.04 \mathrm{~mm}$ long $(n=11)$; vertical plate with projection slightly bilobed at upper margin, antennal horn bifid, $0.05-0.12 \mathrm{~mm}$ long $(n=13)$, antennal base $0.21-0.24 \mathrm{~mm}$ long $(n=13)$; two pairs of lower facial papillae (one asetose and the other setose), three pairs of lateral facial papillae, one pair setose and two without seta. Prothoracic spiracle (Fig. 4) elongate $0.40-0.57 \mathrm{~mm}$ long $(n=14)$, setiform, strongly sclerotized. Prothoracic integument partially rough. Abdominal segments 2-8 with dorsal spines (Table 1 ), spinny dorsal
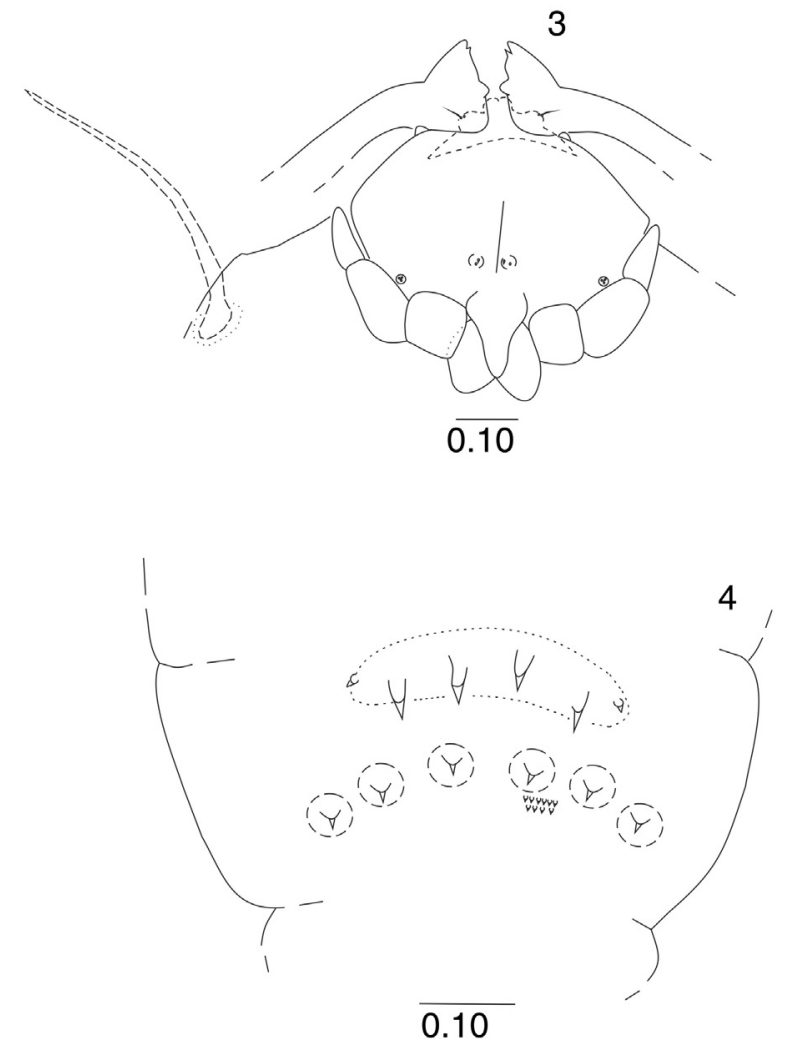

Figs. 3-4. Lopesia leandrae, sp. n., pupa. 4. Head (ventral view). 5. Seventh abdominal segment (dorsal view). Scale bars in $\mathrm{mm}$.

Table 1

Distribution of dorsal spines per abdominal segment in pupa of Lopesia leandrae, sp. n.

\begin{tabular}{llllllll}
\hline & \multicolumn{7}{c}{ Abdominal segment } \\
\cline { 2 - 8 } Number of dorsal spines & 2nd & 3rd & 4 th & 5 th & 6 th & 7 th & 8 th \\
\hline Specimen 1 & 7 & 7 & 6 & 6 & 4 & 5 & 4 \\
Specimen 2 & 4 & 7 & 8 & 7 & 5 & 5 & 3 \\
Specimen 3 & 6 & 5 & 5 & 6 & 5 & 5 & 3 \\
Specimen 4 & 7 & 9 & 6 & 6 & 4 & 5 & 3 \\
Specimen 5 & 6 & 5 & 6 & 6 & 6 & 5 & 4 \\
Specimen 6 & 5 & 7 & 6 & 6 & 5 & 4 & 4 \\
Specimen 7 & 6 & 8 & 7 & 6 & 7 & 6 & 3 \\
Specimen 8 & 5 & 5 & 6 & 5 & 3 & 5 & 3 \\
Specimen 9 & 7 & 7 & 8 & 8 & 8 & 5 & 4 \\
\hline
\end{tabular}

and ventrally. First through sixth abdominal segments with prominent spiracles $(0.07 \mathrm{~mm})$. Terminal segment $(n=7)$ : $0.22-0.25 \mathrm{~mm}$ long, bilobed apically, lobes $0.10-0.14 \mathrm{~mm}$ long

Adult. Male: body length $3.00-3.60 \mathrm{~mm}$ long $(n=7)$ (including terminalia). Head (Fig. 5): apical process absent. Eye facets circular, all closely approximated. Antenna: scape obconical with a single long seta as vestiture, pedicel globose with two rows of several setae, flagellomeres binodal and tricircumfilar; nodes and internodes setulose, necks partially setulose; three circumfila of each flagellomere with short loops (Fig. 6); first and second flagellomeres connate, twelfth flagellomere $0.18-0.19 \mathrm{~mm}$ long $(n=3)$, with apical process entirely setulose $0.05 \mathrm{~mm} \operatorname{long}(n=3)$. Frontoclypeus with 8 setae. Labrum triangular, long-attenuate, with 2 pairs of ventral sensory setae. Hypopharynx with anteriorly directed lateral setulae. Labella elongate-convex, each few long lateral setae and three pairs of short mesal sensory setae. Palpus with three or four segments setose, the first globose, the others cylindrical, $1 \mathrm{st}$ segment shorter than the others; when three-segmented $(n=4)$ : 

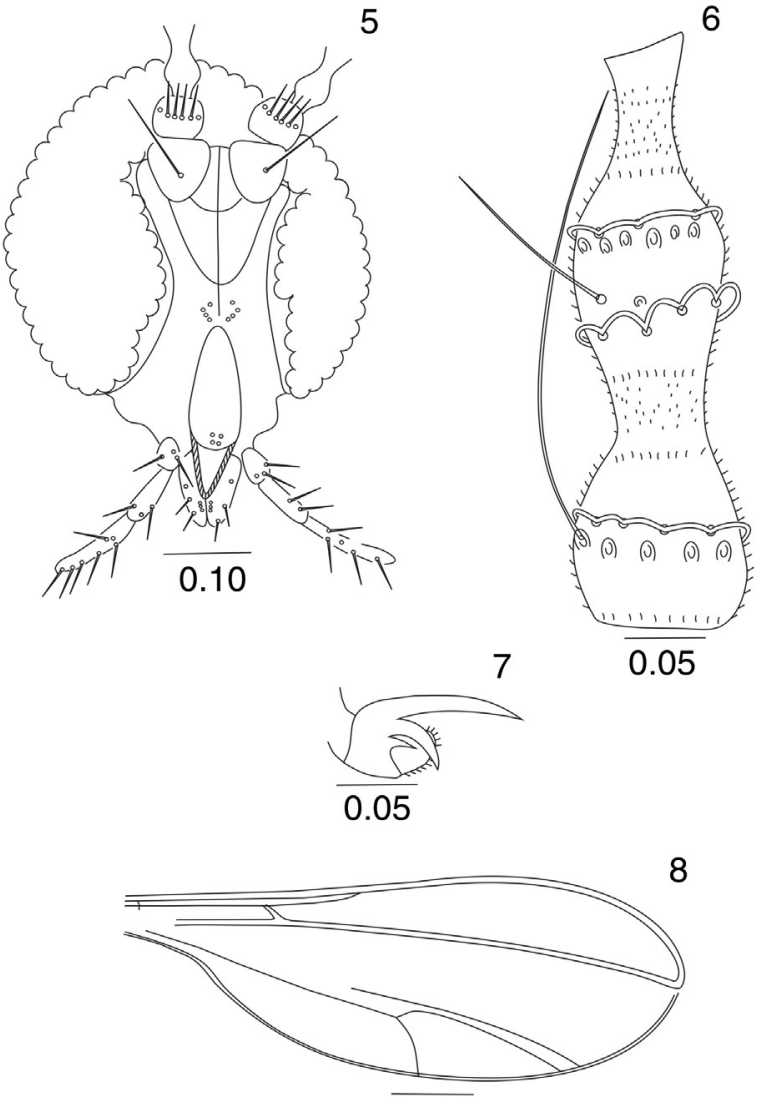

Figs. 5-8. Lopesia leandrae, sp. n., male. 5. Head (frontal view). 6. Fifth flagellomere. 7. Foreleg, tarsal claw and empodium (lateral view). 8. Wing. Scale bars in mm.

1st segment $0.04 \mathrm{~mm}$ long, 2nd segment 0.08 long, 3rd segment $0.10-0.11 \mathrm{~mm}$ long; when four-segmented $(n=1)$ : 1 st segment $0.04 \mathrm{~mm}$ long, 2nd segment 0.06 long, 3rd segment $0.06 \mathrm{~mm}$ long, and 4 th segment $0.07 \mathrm{~mm}$ long (Fig. 7).

Thorax. Wings (Fig. 8): length: $2.30-2.70 \mathrm{~mm}(n=7)$. Venation: $\mathrm{R} 5$ and Rs as in the genus diagnosis, CuA forked, M3 + 4 present. Scutum with 4 longitudinal rows of setae with a few scales intermixed, the 2 dorsocentral rows broadest anteriorly, forming a single row posteriorly, and the 2 lateral as a single row. Scutellum with several scattered setae. Anepisternum bare. Anepimeron with 9 setae. Tarsal claws bent near base and two-toothed, basal tooth shorter than the distal; empodium short, not reaching bend in claws (Fig. 8).

Abdomen (Fig. 9): 1st-6th tergites sclerotized, rectangular, with a single distal row of setae, few setae laterally, basal pair of trichoid sensilla, and scattered scales; 7th tergite sclerotized, rectangular, with only basal pair of trichoid sensilla; 8th tergite sclerotized, narrow, elongated, with only basal pair of trichoid sensilla. 2nd-5th sternites sclerotized, rectangular, with a single distal row of setae, some setae mesally and laterally, basal pair of trichoid sensilla, and scattered scales; 6th sternite sclerotized, rectangular, with a double distal row of setae, several setae mesally and laterally, basal pair of trichoid sensilla, and scattered scales; 7th-8th sternites sclerotized, rectangular, with several setae at $2 / 3$ distal, lateral setae, basal pair of trichoid sensilla and scattered scales. Terminalia (Fig. 10): gonocoxite partially setose, $0.23-0.24 \mathrm{~mm}$ long, $0.08-0.09 \mathrm{~mm}$ wide $(n=06$ ), with setulose mesobasal lobe; gonostylus setulose basally, striated beyond basis, $0.23-0.25 \mathrm{~mm}$ long, $0.02-0.03 \mathrm{~mm}$ wide $(n=06)$; cerci apically rounded with setae and setulae, cercal lobes almost parallel; hypoproct bilobed, with setae and setulae, lobes rounded apically; hypoproct and cercus similar
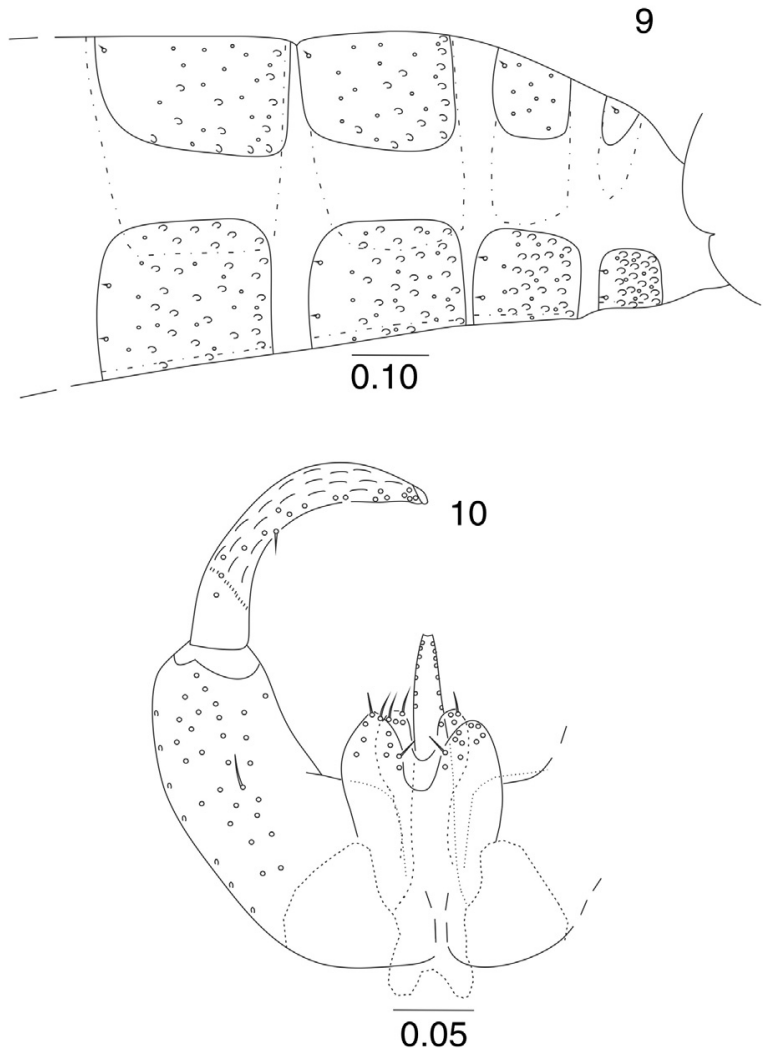

Figs. 9-10. Lopesia leandrae, sp. n., male. 9. 6th-8th abdominal segments (lateral view). 10. Terminalia (dorsal view). Scale bars in $\mathrm{mm}$.

in lenght; aedeagus accentuately longer than hypoproct, tapered to apex, rounded apically, with several asetose papillae laterally.

Adult. Female: body length $3.30-4.40 \mathrm{~mm}$ long $(n=7)$ (including ovipositor). Antenna: scape and pedicel as in male, flagellomeres cylindrical; nodes entirely setulose and necks partially setulose; circumfila as two rings, connected horizontal, not sinuous (Fig. 11), 12th flagellomere $0.13 \mathrm{~mm}$ long $(n=1)$, entirely setulose, apical process $0.04 \mathrm{~mm}$ long $(n=1)$. Frontoclypeus with 7 setae $(n=9)$. Palpus $(n=9)$ : three or four-segmented: the first globose, the others cylindrical, 1st segment shorter than the others; when threesegmented $(n=3)$ : 1 st segment $0.04-0.05 \mathrm{~mm}$ long, 2nd segment 0.08 long, 3rd segment $0.11-0.14 \mathrm{~mm}$ long; when four-segmented $(n=1)$ : 1 st segment $0.03 \mathrm{~mm}$ long, 2nd segment 0.08 long, 3rd segment $0.06 \mathrm{~mm}$ long, and 4 th segment $0.05 \mathrm{~mm}$ long.

Thorax. Wings: length: $2.60-3.20 \mathrm{~mm}(n=7)$. Other features as in male.

Abdomen (Fig. 12): 1st-6th tergites as in male; 7th tergite sclerotized, rectangular, with a double distal row of setae, several setae mesally and laterally, basal pair of trichoid sensilla, and scattered scales, 8th tergite not sclerotized, with only basal pair of trichoid sensilla; 2nd-6th sternites as in male, 7th sternite as in male, 8th sternites not sclerotized, with only basal pair of trichoid sensilla.

Ovipositor barely protrusible, $0.25 \mathrm{~mm}$ long (from basal margin of segment 9 to cerci apex) $(n=1)$, cerci separate elongateovoid, $0.14-0.15 \mathrm{~mm}$ long, $0.04-0.05 \mathrm{~mm}$ wide $(n=3)$ and setose, hypoproct with setae and setulae (Fig. 13).

Etymology. The name leandrae refers to the host plant genus.

Material examined. Holotype male. Brazil, São Paulo: Bertioga, Fazenda Pinto, 22.V.2004, V. Maia col., MNRJ. Paratypes, same locality, data and collector - 2 males, 3 females; same locality and collector - 26/VIII/2004 - 9 pupal exuviae; 23.IX.2004 -2 pupal exuviae and 1 female 17/XI/2004 - 2 larvae, 2 pupal exuviae, 2 females; 27/IV/2005, 3 larva; 16/V/2005 - 1 larva; 17/V/ 

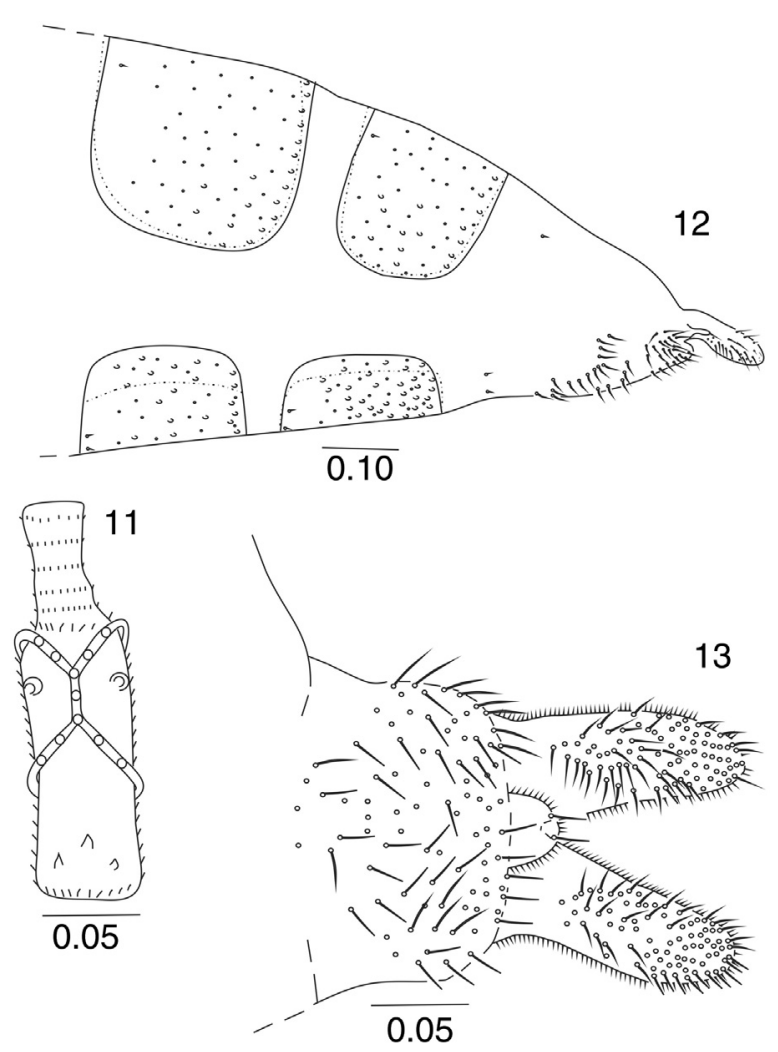

Figs. 11-13. Lopesia leandrae, sp. n., female. 11. Fifth flagellomere. 12. 6th-8th abdominal segments (lateral view). 13. Cerci (ventral view). Scale bars in $\mathrm{mm}$.

2005 - 1 larva; Bertioga, Itaguaré, same collector, 23/V/2004 - 1 larva; 30.VII.2004 - 3 larvae; 24/VIII/2004 - 1 male; 30/VIII/2004 -1 male; 21/IX/2004 - 2 pupal exuviae, 20/X/2004 - 1 female; 16/XI/2004 - 4 larvae; 29/III/2005 - 1 larva and 3 pupal exuviae, MNRJ.

Distribution. Brazil: São Paulo, Bertioga.

Comments. Lopesia includes adults with bare or setulose flagellomeres neck. The new species has setulose flagellomeres neck as in L. andirae Garcia, Lima, Calado \& Urso-Guimarães, 2017, L. brasiliensis Rübsaamen, 1908; L. caulinaris Maia, 2003; L. conspicua Maia, 2003; L. davillae Maia, 2017; L. eichhorniae Urso-Guimarães, 2014; L. elliptica Maia, 2013; L. erythroxyli Rodrigues \& Maia,
2010; L. indaensis Maia \& Oliveira, 2018; L. linearis Maia, 2003; L. marginalis Maia, 2001; L. maricaensis Rodrigues \& Maia, 2010; L. similis Maia, 2004; L. simplex Maia, 2002; L. tibouchinae Maia, 2004; and L. ubatubensis Garcia and Urso-Guimarães, 2018. Among them, only L. maricaensis has binodal male flagellomeres and all circumfila with reduced loops as in the new species.

Nevertheless, $L$. leandrae differs from $L$. maricensis in the following morphological aspects: (1) tarsal claws: with a single tooth in $L$. maricensis, with two teeth in L. leandrae; (2) relative length between gonocoxites and gonostyli: gonostyli longer than gonocoxites in $L$. maricensis and shorter in L. leandrae; (3) antennal horns (pupa): simple and relatively short in $L$. maricensis, toothed and longer in L. leandrae; (4) abdominal dorsal spines (pupa): absent in L. maricensis and present in L. leandrae; (5) terminal segment (larva): with two terminal lobes widely separate from each other only in L. leandrae; (6) gall shape: $L$. maricensis induces marginal leaf rolls and $L$. leandrae complex leaf galls (globoid and with trichomes).

\section{Conflicts of interest}

The authors declare no conflicts of interest.

\section{Acknowledgments}

I am grateful to the Conselho Nacional de Desenvolvimento Científico e Tecnológico (CNPq) for financial support (Proc. 301481/2017-2).

\section{References}

Cumming, J.M., Wood, D.M., 2009. Adult morphology and terminology. In: Brown, B.V., Borkent, A., Cumming, J.M., Wood, D.M., Woodley, N.E., Zumbado, M.A. (Eds.), Manual of Central American Diptera, vol. 1. NRC Research Press, Ottawa, pp. 9-50, 714 p.

Flora do Brasil, 2019. Flora do Brasil 2020 under construction. Jardim Botânico do Rio de Janeiro. Available from: http://floradobrasil.jbrj.gov.br/ [accessed 12.02.19].

Gagné, R.J., 1989. The Plant-Feeding Gall Midges of North America. Cornell University Press, Comstock, pp. 356.

Gagné, R.J., Jaschhof, M., 2017. A Catalog of the Cecidomyiidae (Diptera) of the World, 4rd ed. Digital version.

Garcia, C.A., Urso-Guimarães, V., 2018. Three new species of Lopesia Rübsaamen (Diptera: Cecidomyiidae) from Brazil. Florida Entomol. 101 (2), 203-211.

Maia, V.C., Magenta, M.A.G., Martins, S.E., 2008. Ocorrência e caracterização de galhas de insetos em áreas de restinga de Bertioga (São Paulo Brasil). Biota Neotrop. 8 (1), 167-197.

Maia, V.C., Oliveira, L.A., 2018. Lopesia indaiensis (Diptera, Cecidomyiidae), a new species of gall midge feeding on Andira fraxinifolia Benth (Fabaceae), an endemic plant in Brazil. Rev. Bras. Entomol 62, 125-130. 